\title{
Recurrent Network Interactions Underlying Flow-Field Selectivity of Visual Interneurons
}

\author{
Juergen Haag and Alexander Borst \\ Division of Insect Biology, Department of Environmental Science, Policy, and Management, University of California, \\ Berkeley, California 94720-3112
}

\begin{abstract}
Motion-sensitive large-field neurons found at higher processing stages in many species often exhibit a remarkable selectivity for particular flow fields. However, the underlying neural mechanisms are not yet understood. We studied this problem in the so-called lobula plate tangential cells (LPTCs) of the fly. Investigating the connectivity between LPTCs by means of dual recordings, we find two types of connections: (1) heterolateral connections between LPTCs of both hemispheres and (2) ipsilateral connections between LPTCs within one lobula plate. The
\end{abstract}

circuit is suitable to amplify incoming, dendritic signals in the case of rotatory flow fields and to reduce them in the case of other flow-field structures. In addition to feedforward connectivity, thus, the flow-field selectivity of LPTCs may be significantly attributable to recurrent excitation involving the network of large-field neurons in both brain hemispheres.

Key words: network interactions; motion detection; insect; vision; electrophysiology; dendrite
For visual course control, motion cues play a dominant role. Therefore, it is not surprising to find motion-sensitive neurons with large and often complex receptive fields at higher processing stages in the visual system of many species, like area MST in monkeys (Tanaka and Saito, 1989; Tanaka et al., 1989; Duffy and Wurtz, 1991a,b), the lateral suprasylvian cortex of cats (Rauschecker et al., 1987), the nucleus BOR (Wylie and Frost, 1999) or nucleus rotundus (Wang and Frost, 1992) of pigeons, and the lobula plate of flies (Hausen, 1984; Krapp and Hengstenberg, 1996; Krapp et al., 1998). Such receptive field structures can in principle arise via input from respectively oriented small-field elements alone. However, the response selectivity may be further enhanced via network interactions between various large-field neurons. Because within each hemisphere of the blowfly the lobula plate contains only $\sim 60$ individually identifiable such neurons [lobula plate tangential cells (LPTCs)] (Hausen, 1982a,b; Hengstenberg, 1982; Hengstenberg et al., 1982; Borst and Haag, 1996), this system lends itself well to a detailed analysis of the mechanisms underlying flow-field selectivity of motion-sensitive large-field neurons.

Almost all LPTCs respond to visual motion in a directionally selective way (Borst and Egelhaaf, 1989, 1990; Single et al., 1997; Single and Borst, 1998). Among them are the graded potential horizontal system (HS) and centrif ugal horizontal $(\mathrm{CH})$ cells. HS cells differ from $\mathrm{CH}$ cells by their active membrane properties (Hengstenberg, 1977; Haag and Borst, 1996; Haag et al., 1997) as well as with respect to their synaptic organization (Hausen et al., 1980; Eckert and Meller, 1981; Gauck et al., 1997). There exist two $\mathrm{CH}$ cells in each brain hemisphere [a dorsal $\mathrm{CH}(\mathrm{dCH})$ and a ventral $\mathrm{CH}(\mathrm{vCH})$ ] and three HS cells [the HS northern (HSN),

Received March 19, 2001; revised May 7, 2001; accepted May 8, 2001.

This work was supported by National Institutes of Health Grant 1RO1MH61598-01 to A.B. We are grateful to Dr. Michael Dickinson for critically reading this manuscript.

Correspondence should be addressed to Dr. Alexander Borst, 201 Wellman Hall, ESPM-Division of Insect Biology, University of California, Berkeley, CA 947203112. E-mail: borst@nature.berkeley.edu.

Copyright (C) 2001 Society for Neuroscience $\quad 0270-6474 / 01 / 215685-08 \$ 15.00 / 0$ the HS equatorial (HSE), and the HS southern (HSS) cell]. The different members of each family occupy different regions within the lobula plate and, because of the retinotopic organization, have different but often overlapping receptive fields together covering almost completely the visual space surrounding the animal.

In contrast to $\mathrm{HS}$ and $\mathrm{CH}$ cells, which restrict their ramifications to one brain hemisphere, the $\mathrm{H} 1$ and $\mathrm{H} 2$ cells (Eckert, 1980; Hausen, 1981) are purely spiking neurons and project with their axon toward the other brain hemisphere ("heterolateral elements"). The H1 cell has been used in many studies to explore the nature of the neural code (Bialek et al., 1991; de Ruyter van Steveninck et al., 1997; Haag and Borst, 1997, 1998). H1 and H2 cells connect to $\mathrm{HS}$ and $\mathrm{CH}$ cells, thus conveying motion information from one-half of the visual surround to neurons that receive motion information on their main dendrite about the other half of the visual surround (Hausen, 1977, 1981, 1984; Eckert and Dvorak, 1983; Haag, 1994; Haag et al., 1999; Horstmann et al., 2000). As a result, $\mathrm{HS}$ and $\mathrm{CH}$ cells respond not only to motion in front of the ipsilateral eye but also to motion in front of the contralateral eye.

In the following, we investigate the connectivity between LPTCs within one lobula plate as well as between the lobula plates of both brain hemispheres. We find that a large number of recurrent feedback loops exists involving cells of both hemispheres that support and stabilize the selectivity for rotatory flow fields over translatory ones.

\section{MATERIALS AND METHODS}

Preparation and setup. Female blowflies (Calliphora vicina) were briefly anesthetized with $\mathrm{CO}_{2}$ and mounted ventral side up with wax on a small preparation platform. The head capsule was opened from behind; the trachea and air sacs that normally cover the lobula plate were removed. To eliminate movements of the brain caused by peristaltic contractions of the esophagus, the proboscis of the animal was cut away, and the gut was pulled out. This allowed stable intracellular recordings of up to $45 \mathrm{~min}$. The fly was then mounted on a heavy recording table looking down onto the stimulus monitors. The fly brain was viewed from behind through a fluorescence microscope (Axiotech Vario $100 \mathrm{HD}$; Zeiss). 


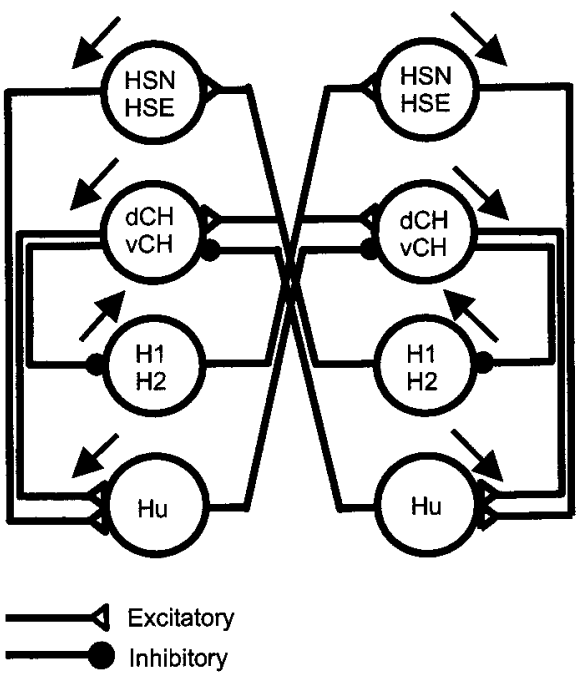

Figure 1. Summary diagram about the connections between large-field lobula plate neurons characterized in this study. Excitatory connections are shown as open triangles; inhibitory connections are shown as filled circles. Black arrows indicate the preferred direction of visual motion on the ipsilateral side of the cells.

Stimulation. Stimuli were generated on Tektronix 608 monitors by an image synthesizer (Picasso; Innisfree) and consisted of a onedimensional grating of $16.7^{\circ}$ spatial wavelength and $87 \%$ contrast displayed at a frame rate of $200 \mathrm{~Hz}$. The mean luminosity of the screen was $11.2 \mathrm{~cd} / \mathrm{m}^{2}$. The intensity of the pattern was square wave modulated along its horizontal axis. The stimulus field extended from 16 to $42^{\circ}$ for the left eye and from 16 to $48^{\circ}$ for the right eye in the horizontal direction and from -30 to $+30^{\circ}$ in the vertical direction of the fly.

Electrical recording. For intracellular recordings of the cells, electrodes were pulled on a Brown-Flaming micropipette puller (P-97) using thinwall glass capillaries with an outer diameter of $1 \mathrm{~mm}$ (Clark; GC100TF10). The tip of the electrode was filled with $8.8 \mathrm{~mm} \mathrm{Ca-green} \mathrm{(Ca-green-1}$ hexapotassium salt; Molecular Probes, Eugene, OR). The shaft of the electrode was filled with a $2 \mathrm{M} \mathrm{KCl}$ solution. Resistances were $\sim 15 \mathrm{M} \Omega$. For dual intracellular recordings of two cells in the same brain hemisphere (see Fig. 6), one electrode was filled with the green fluorescent dye $\mathrm{Ca}$-green, and the other electrode was filled with the red fluorescent dye Alexa 568 (Molecular Probes). A SEL10 amplifier (npi electronics) that was operated in the bridge mode was used throughout the experiments. In the experiments with dual intracellular recordings, we used an additional SEL10 amplifier. When we accompanied the intracellular recording with a simultaneous extracellular recording from a spiking neuron, we used standard tungsten electrodes with a resistance of $\sim 2$ $\mathrm{M} \Omega$. Extracellular signals were amplified, bandpass filtered, and subsequently processed by a threshold device delivering a $100 \mathrm{mV}$ pulse of 1 msec duration on each spike detected. For data analysis the output signal of the amplifiers (SEL10 and SEL10/threshold device) was fed to a PIII personal computer via a 12 bit analog-to-digital converter (DAS-1602/12; Computerboards, Middleboro, MA) at a sampling rate of $5 \mathrm{kHz}$ and stored on a hard disk.

The signals were evaluated off-line by a program written in Delphi (Borland). The number of EPSPs and IPSPs (see Figs. 4, 6) in the intracellular recorded responses were detected by high-pass filtering $(t=$ $10 \mathrm{msec}$ ) the response traces and applying a threshold operation.

\section{RESULTS}

Our findings are summarized in the circuit diagram presented in Figure 1. For the sake of simplicity, each neuron is represented by a circle. We, thus, do not specify where on the neuron another neuron is making contacts and is eliciting postsynaptic potentials. Because $\mathrm{H} 1$ and $\mathrm{H} 2$ cells have identical properties in many respects, we do not differentiate between them in this scheme. From the HS cell family, the HSS cell is omitted because it does not receive contralateral input (Hausen, 1982a; Haag, 1994). The top two cell groups shown are the graded potential neurons of the HS and $\mathrm{CH}$ cell family; below are the heterolateral spiking neurons H1, H2, and Hu [called "U" in Hausen (1984)]. The first characteristic of the circuit is that both $\mathrm{HS}$ and $\mathrm{CH}$ cells receive contralateral input from $\mathrm{H} 1$ and $\mathrm{H} 2$; $\mathrm{CH}$ cells in addition receive from $\mathrm{Hu}$. These connections form the basis for the sensitivity of both $\mathrm{HS}$ and $\mathrm{CH}$ cells to visual motion stimuli presented in front of the contralateral eye. As we will show below, $\mathrm{HS}$ and $\mathrm{CH}$ cells influence those heterolateral spiking neurons the dendrites of which are located on the ipsilateral side. The ipsilateral connections are such that they excite those heterolateral neurons that have the same preferred direction and inhibit the ones with the opposite preferred direction. This leads to a suppression of the activity of the contralateral $\mathrm{HS}$ and $\mathrm{CH}$ cells after excitation of $\mathrm{HS}$ and $\mathrm{CH}$ cells on the ipsilateral side of the brain. The circuit, thus, favors motion stimuli that lead to an inhibition on one side and to an excitation on the other side. Such bilateral interactions indeed have been described previously in the literature (McCann and Foster, 1971). Furthermore, following the connections through a complete loop, from one side to the other side of the brain and back again, we see that positive, recurrent feedback loops are implemented in the circuit; whatever way one chooses, activity in one cell will never lead to its own inhibition, because one complete loop comprises always two inhibitory synapses. Evidence supporting these ideas will now be presented.

\section{Contralateral input}

The intracellular recording from a dCH cell and the simultaneous extracellular recording from the spiking $\mathrm{H} 2$ cell of the other brain hemisphere showed that the spikes of the $\mathrm{H} 2$ cell and the largeamplitude EPSPs in the $\mathrm{dCH}$ cell coincide (Fig. 2a). Each spike in the $\mathrm{H} 2$ cell was followed by an EPSP in the $\mathrm{dCH}$ cell. This is further substantiated by the spike-triggered average (Fig. $2 b$ ) in which each spike of the $\mathrm{H} 2$ cell was used to cut out a stretch of $\mathrm{dCH}$ signals that were all subsequently averaged. A similar double recording was made from a dCH cell and an $\mathrm{H} 1$ cell. Figure $2 c$ shows the spike-triggered average of the $\mathrm{dCH}$ signal with the $\mathrm{H} 1$ spikes as a trigger. This demonstrates that the two differently sized EPSPs in $\mathrm{dCH}$ cells can be attributed unequivocally to spikes in $\mathrm{H} 1$ and $\mathrm{H} 2$ cells. The absence of failures and the negligible delay between the action potentials and the EPSPs indicate a monosynaptic connection between $\mathrm{H} 1, \mathrm{H} 2$, and the $\mathrm{dCH}$ cell. The same type of experiment was done for a vCH cell and for two cells of the horizontal system, the HSE and HSN cells (data not shown). We found that all of these cells receive identical excitatory input from the spiking heterolateral neurons $\mathrm{H} 1$ and H2 (see also Fig. 6). However, IPSPs could be detected only in $\mathrm{vCH}$ and $\mathrm{dCH}$ cells but not in HS cells (see Fig. $6 d$ ). The neuron eliciting the IPSPs has not yet been determined. In this manuscript we will refer to it as $\mathrm{Hu}$ (u for unknown).

Because the axonal terminals of the $\mathrm{H} 1$ cell are located in the lobula plate, whereas $\mathrm{H} 2$ terminates in the protocerebrum, it was expected that $\mathrm{CH}$ cells receive the $\mathrm{H} 1$ input on the arborizations in the lobula plate, whereas the input of the $\mathrm{H} 2$ cell impinges on the arborization in the protocerebrum. For the reasons outlined above, no knowledge was available for the likely origin of the IPSPs. To investigate where on the $\mathrm{CH}$ cell the IPSPs originate and to verify the location of the input of $\mathrm{H} 1$ and $\mathrm{H} 2$ cells on the $\mathrm{CH}$ cells, we performed dual intracellular recordings of a $\mathrm{dCH}$ cell with one electrode in the axon near the lobula plate (LP electrode) and the other electrode in the axon near the protocerebral ramifications (PC electrode) (Fig. $2 d$ ). In the case of the H1 

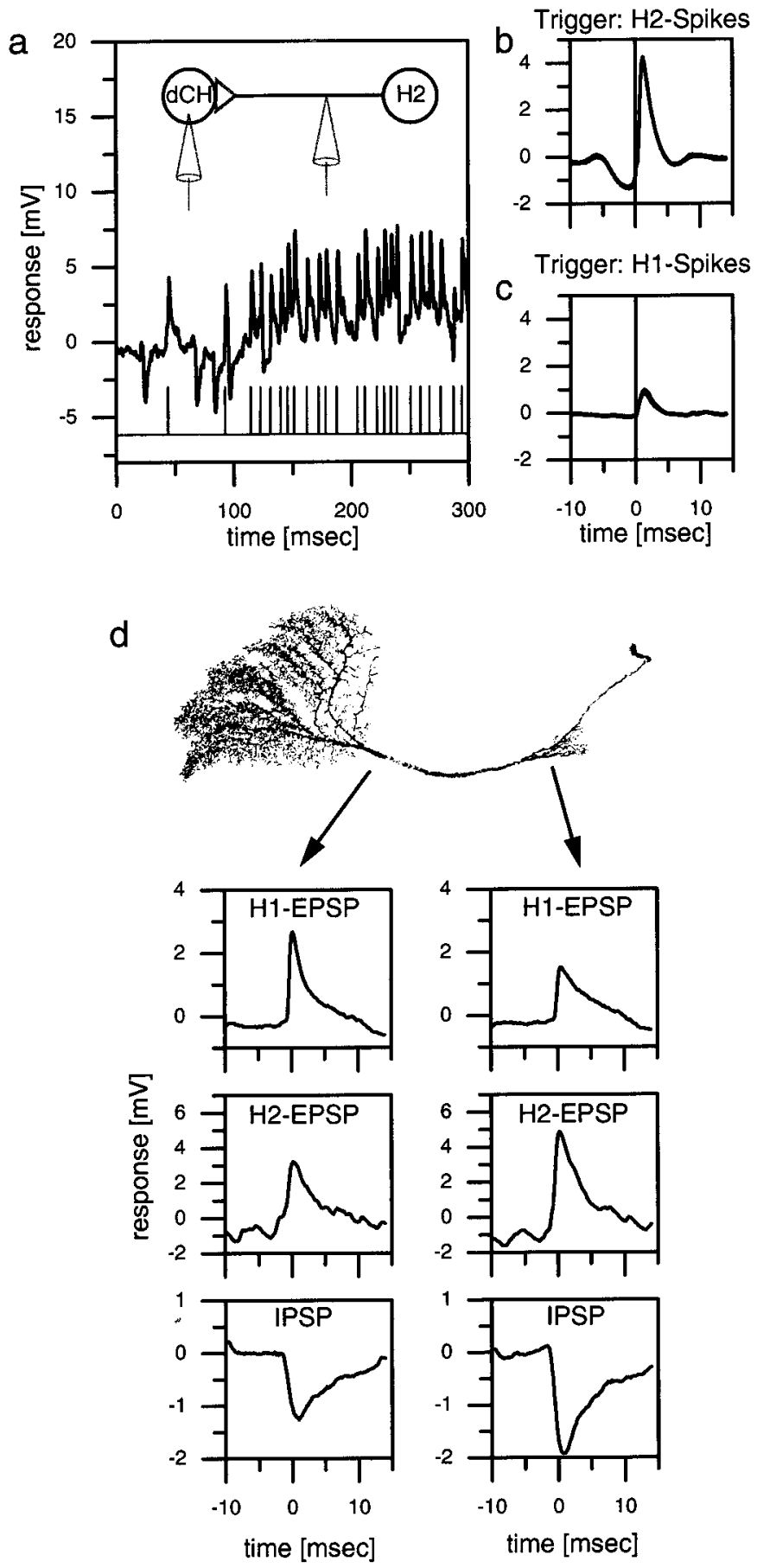

Figure 2. $a-c$, Double recording of an $\mathrm{H} 1$ or an $\mathrm{H} 2$ cell and a dCH cell. $a$, Single trace of an intracellular dCH cell recording and an extracellular $\mathrm{H} 2$ recording. Each extracellular recorded spike in the $\mathrm{H} 2$ elicits an largeamplitude EPSP in the dCH cell. $b, \mathrm{H} 2$ spike-triggered average of the $\mathrm{dCH}$ cell signal. The peak of the EPSP occurs $\sim 1$ msec after the spike of the $\mathrm{H} 2$ (vertical line). $c, \mathrm{H} 1$ spike-triggered average of the $\mathrm{dCH}$ cell signal. The amplitude of the averaged EPSP is only one-third that of the H2-triggered EPSP. $d$, Dual electrode intracellular recording from a dCH cell. The location of the recording electrodes indicated by the origin of the arrows on a reconstructed $\mathrm{dCH}$ cell is shown. Left plots, The averaged H1 EPSPs (top), H2 EPSPs (middle), and IPSPs (bottom) of the lobula plate electrode. Right plots, The respective signals of the protocerebral electrode. In the dendritic recording, the amplitude of H1 EPSPs is larger than that of the protocerebral recording. H2 EPSPs and IPSPs are larger in the protocerebral recording. Similar data have been obtained in three additional preparations $(\mathrm{dCH}, n=2 ; \mathrm{vCH}, n=1)$. a

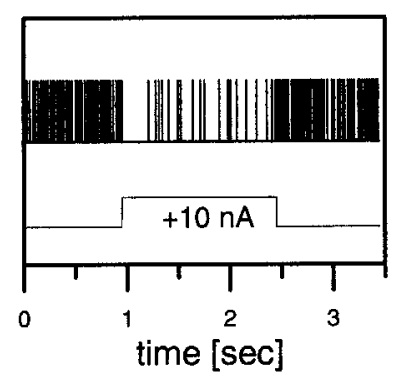

b
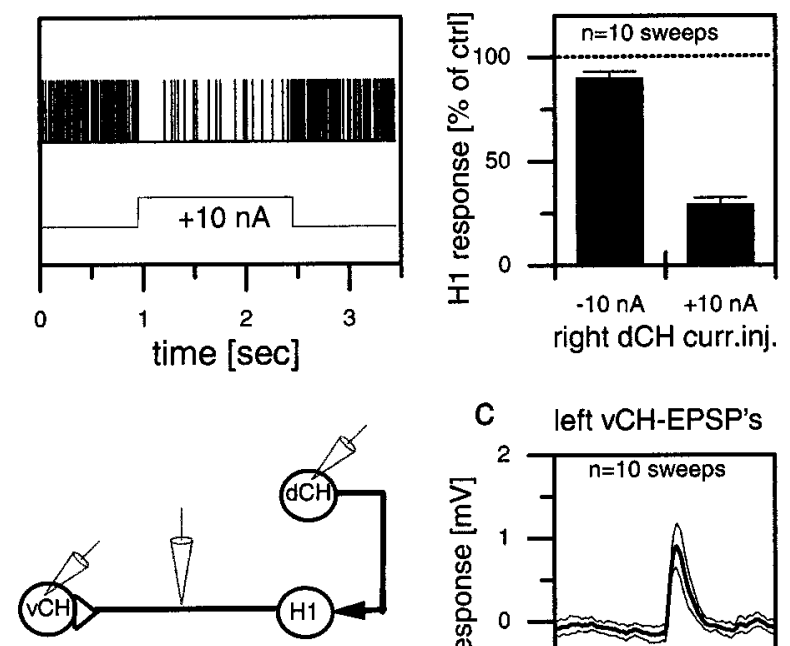

C left $\mathrm{VCH}$-EPSP's

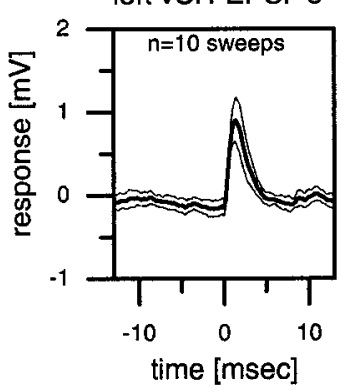

d
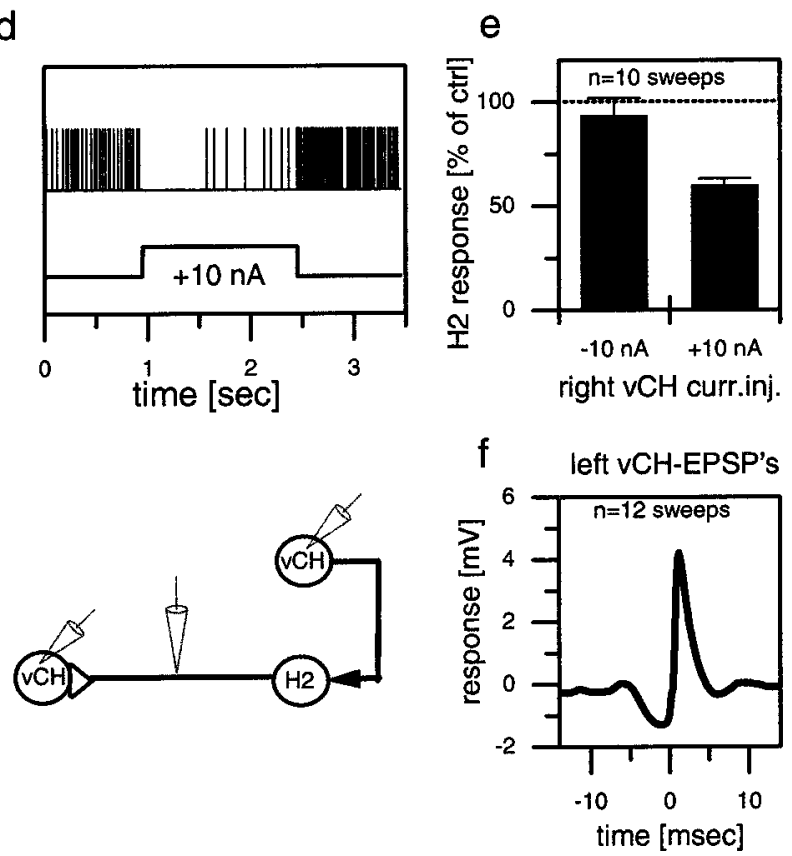

Figure 3. Extracellular recording of a spiking neuron and simultaneous intracellular recording of a $\mathrm{CH}$ cell in the same brain hemisphere $(a, b, d$, $e)$ or in the opposite hemisphere $(c, f)$. The top graphs $(a-c)$ show results obtained from a dCH $\rightarrow \mathrm{H} 1 \rightarrow \mathrm{vCH}$ cell recording; the bottom graphs $(d-f)$ show the results for the $\mathrm{vCH} \rightarrow \mathrm{H} 2 \rightarrow \mathrm{vCH}$ cell recording. $a$, $d$, Singleresponse trace of $\mathrm{H} 1(a)$ and $\mathrm{H} 2(d)$ in response to current injected into the ipsilateral $\mathrm{CH}$ cell. $b, e$, Spike frequency of $\mathrm{H} 1(b)$ and $\mathrm{H} 2(e)$ as a function of depolarization or hyperpolarization of the $\mathrm{CH}$ cell. The error bars show the average and the SEM of 10 sweeps for H1 $(b)$ and 10 sweeps for $\mathrm{H} 2(e) . c, f$, Spike-triggered average and SEM of the membrane potential of the contralateral $\mathrm{CH}$ cell, recorded within the same fly in the opposite brain hemisphere. Similar data have been obtained in four other experiments comprising all combinations at least once. They demonstrate that depolarization of the $\mathrm{dCH}$ as well as the $\mathrm{vCH}$ cell reduces spike activity in the $\mathrm{H} 1$ as well as the $\mathrm{H} 2$ cell. ctrl, Control; curr.inj., current injection. 
Figure 4. Simultaneous intracellular recordings of two $\mathrm{dCH}$ cells, one in the left and one in the right lobula plate. $a$, Fluorescence image of the cells filled with $\mathrm{Ca}$ green. $b$, Visual responses of both cells to rotatory motion stimuli in front of the fly. $c$, Single-response trace of the left $\mathrm{dCH}$ cell in response to hyperpolarization and depolarization of the right $\mathrm{dCH}$ cell. Hyperpolarization led to a decreased IPSP frequency compared with resting; depolarization led to an increased IPSP frequency and a decreased EPSP frequency. $d, e$, These effects quantified further. Hyperpolarization of the right $\mathrm{dCH}$ cell suppressed IPSP frequency of the left $\mathrm{dCH}$ almost completely (d) but had no significant effect on its EPSP frequency $(e)$. Depolarization of the right frequency in the left dCH cell $(d)$ and decreased the EPSP frequency to $\sim 30 \%$ of the control condition $(e)$. $\mathrm{dCH}$ cell led to a threefold increase of IPSP
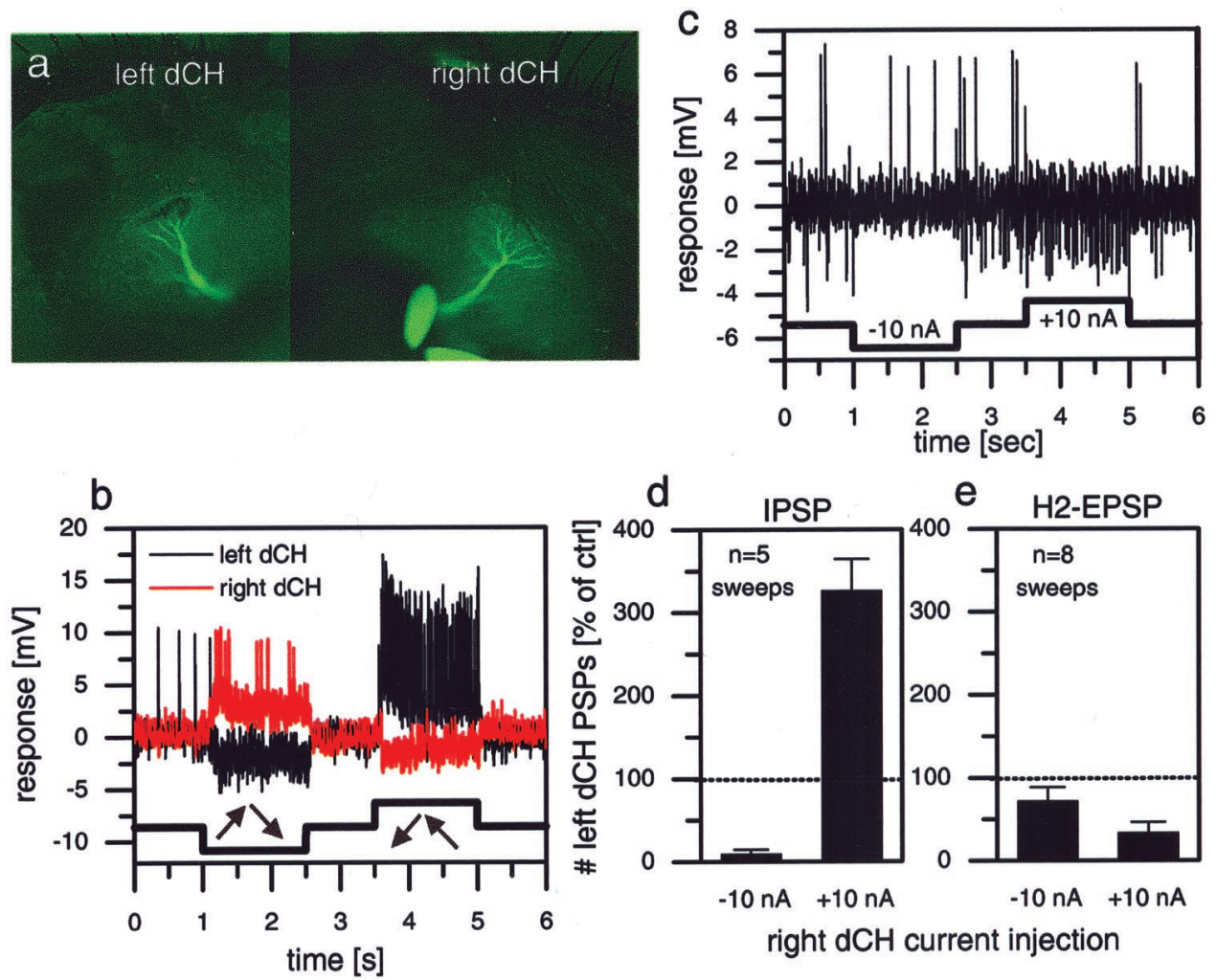

input, the EPSPs recorded with the LP electrode were found to have a larger amplitude than the H1 EPSPs recorded with the PC electrode (Fig. 2d, top plots). The opposite is true for the $\mathrm{H} 2$ input. For these EPSPs, the PC electrode recorded bigger EPSP amplitudes (Fig. 2d, middle plots). The IPSPs seem to originate in the protocerebral ramifications of the $\mathrm{CH}$ cell because the signals recorded with the $\mathrm{PC}$ electrode were larger than the ones recorded with the LP electrode (Fig. $2 d$, bottom plots). In summary, this indicates that the $\mathrm{dCH}$ cell receives the $\mathrm{H} 1$ input via its lobula plate arborization, whereas the $\mathrm{H} 2$ input and the input responsible for the IPSPs are located at the protocerebral arborization. These findings support the anatomical observations in the case of the $\mathrm{H} 1$ and $\mathrm{H} 2$ inputs and show that the site of the synaptic connection between the $\mathrm{dCH}$ and the $\mathrm{Hu}$ is likely to be the protocerebral ramification of the $\mathrm{CH}$ cell.

\section{Ipsilateral output}

Whereas the above results demonstrated the effects of the contralateral spiking cells on the $\mathrm{CH}$ and $\mathrm{HS}$ cells, the next series of experiments dealt with the effect of $\mathrm{CH}$ and $\mathrm{HS}$ cells on the ipsilateral counterparts of these spiking cells, i.e., $\mathrm{H} 1$ and $\mathrm{H} 2$ cells that have their dendrites within the same lobula plate as the $\mathrm{CH}$ and HS cells. To investigate these ipsilateral connections, we recorded intracellularly from $\mathrm{CH}$ cells and extracellularly from $\mathrm{H} 1$ and $\mathrm{H} 2$ on the same side of the brain. Figure 3 shows the effect of depolarization of a dCH cell on the resting firing frequencies of an $\mathrm{H} 1$ cell (Fig. $3 a, b)$ and the effect of depolarization of a $\mathrm{vCH}$ cell on an $\mathrm{H} 2$ cell (Fig. $3 d, e$ ). Depolarization of $\mathrm{CH}$ cells resulted in a strong reduction of the mean firing frequency of the $\mathrm{H} 1$ cell as well as of the $\mathrm{H} 2$ cell. In contrast, hyperpolarization of the $\mathrm{CH}$ cells seemed to have only a small, if any, effect. In contrast to $\mathrm{CH}$ cells, the depolarization of HS cells did not have any effect on the firing frequency of the $\mathrm{H} 1$ or $\mathrm{H} 2$ cells (data not shown, but see Fig. 5).
Because the identification of an individual cell type may be problematic in extracellular recordings, we performed additional control experiments to overcome this limitation. Having established the inhibitory connection of the $\mathrm{CH}$ onto the spiking cell, the intracellular electrode was withdrawn from the $\mathrm{CH}$ cell, and a $\mathrm{CH}$ cell on the other side of the brain was recorded. The extracellular electrode remained in place. The spike-triggered average of the extracellularly recorded cell and the $\mathrm{CH}$ cell revealed the EPSPs (Fig. 3c,f) shown above in Figure 2, $b$ and $c$. This experiment was done for the two combinations shown here, i.e., right $\mathrm{dCH} \rightarrow$ right $\mathrm{H} 1 \rightarrow$ left $\mathrm{vCH}$ (Fig. 3a-c) and right $\mathrm{vCH} \rightarrow$ right $\mathrm{H} 2 \rightarrow$ left vCH (Fig. $3 d-f$ ). The results unequivocally demonstrate that exactly those spiking cells that are inhibited by $\mathrm{CH}$ cells on the same side of the brain are responsible for the EPSPs in $\mathrm{CH}$ cells on the other side of the brain.

\section{Bilateral interactions}

From the above experiments, $\mathrm{CH}$ cells of one brain hemisphere are expected to influence the response of the $\mathrm{CH}$ cells on the opposite half of the brain via $\mathrm{H} 1$ and $\mathrm{H} 2$ cells. In the following set of experiments, we directly tested these bilateral interactions in dual intracellular recordings from two $\mathrm{CH}$ cells with one electrode in the left and one in the right brain hemisphere. The experiments furthermore were aimed to investigate the influence of $\mathrm{CH}$ cells on $\mathrm{Hu}$ cells because the latter could not be directly recorded but were made visible via the IPSPs they elicit in the contralateral $\mathrm{CH}$ cells.

The example that is shown in Figure 4 was performed on two $\mathrm{dCH}$ cells. Both cells were filled with $\mathrm{Ca}$-green to allow for their anatomical characterization (Fig. $4 a$ ). Because both cells have the same preferred direction (front to back), rotatory motion in one direction excited one cell and inhibited the other and vice versa (Fig. 4b). As can be seen in the single trace (Fig. 4c), injection of current into one $\mathrm{CH}$ cell had a strong effect on the occurrence of 
a
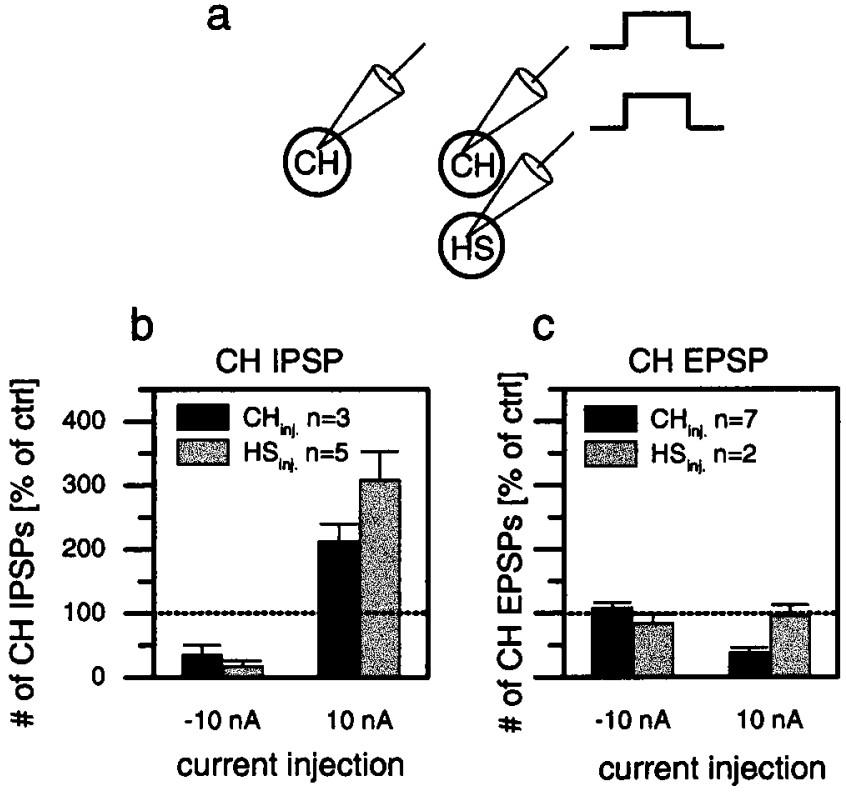

Figure 5. Summary of the effects of hyperpolarization and depolarization of $\mathrm{CH}$ cells (black bars) and HS cells ( gray bars) on the frequency of IPSPs $(b)$ and EPSPs $(c)$ of $\mathrm{CH}$ cells in the opposite brain hemisphere. $b$, Depolarization and hyperpolarization of HS cells had a stronger effect on the frequency of IPSPs than the depolarization and hyperpolarization of $\mathrm{CH}$ cells had. $c$, In contrast, the frequency of EPSPs was not affected by current injection in $\mathrm{HS}$ cells, whereas depolarization of $\mathrm{CH}$ cells decreased the frequency of EPSPs. Data are compiled from a total of 10 experiments performed on different flies that comprise the following cell pairs: $\mathrm{dCH}-\mathrm{dCH}(n=1), \mathrm{dCH}-\mathrm{HSN}(n=1), \mathrm{dCH}-\mathrm{vCH}(n=3)$, dCH-HSE $(n=2)$, vCH-HSE $(n=2)$, and vCH-vCH $(n=1)$. inj., Injection.

IPSPs in the $\mathrm{CH}$ cell of the opposite brain hemisphere; injection of hyperpolarizing current reduced the number of IPSPs, whereas the injection of depolarizing current increased the number of IPSPs (Fig. 4d). As expected from the experiments shown in Figure 3, injection of current in one $\mathrm{CH}$ cell also altered the frequency of EPSPs in the other $\mathrm{CH}$ cell; whereas hyperpolarization had only a weak effect, depolarization of the $\mathrm{dCH}$ cell decreased the frequency of the H2 EPSPs recorded in the other cell substantially (Fig. 4e). As is also expected from the recordings shown in Figure 3, depolarization of one $\mathrm{CH}$ cell affected not only the frequency of $\mathrm{H} 2$ EPSPs in the other $\mathrm{CH}$ cell but also the frequency of H1 EPSPs. This was shown in other recordings that allowed for a distinction between H1- and H2-elicited EPSPs (data not shown).

Figure 5 summarizes the effects of current injection into HS and $\mathrm{CH}$ cells on one side of the brain on $\mathrm{CH}$ cells on the other side of the brain (Fig. 5a) from a total of 10 experiments performed in different flies. Injection of hyperpolarizing current into $\mathrm{CH}$ or HS cells led to a decrease in IPSP frequency; injection of depolarizing current into $\mathrm{CH}$ or $\mathrm{HS}$ cells led to an increase in IPSP frequency (Fig. 5b). Thus, $\mathrm{CH}$ and HS cells had the same effect on the IPSP frequency in the $\mathrm{CH}$ cell of the opposite brain hemisphere; the only difference was that the effects of current injected into HS cells were found to be more pronounced than when current was injected into $\mathrm{CH}$ cells. In contrast, depolarization of HS cells had no effect on the frequency of EPSPs in $\mathrm{CH}$ cells, whereas injection of depolarizing current into $\mathrm{CH}$ cells reduced the EPSP frequency significantly (Fig. $5 c$ ). In both $\mathrm{CH}$ and HS cells, injection of hyperpolarizing current did not affect the EPSP frequency in $\mathrm{CH}$ cells of the opposite brain hemisphere.

In summary the experiments presented above demonstrate that the $\mathrm{CH}$ cells on opposite sides of the brain influence each other via the heterolateral elements $\mathrm{H} 1, \mathrm{H} 2$, and $\mathrm{Hu}$. By inhibiting the elements with the opposite preferred direction on the ipsilateral side, i.e., $\mathrm{H} 1$ and $\mathrm{H} 2, \mathrm{CH}$ cells inhibit the excitatory input onto the opposite $\mathrm{CH}$ cells during front-to-back motion. Hyperpolarization, however, does not have an effect on EPSP frequency in the opposite $\mathrm{CH}$ cell. In contrast, the influence of $\mathrm{CH}$ cells on the $\mathrm{Hu}$ cell is an excitatory one and operates in both directions; inhibition of $\mathrm{CH}$ cells inhibits $\mathrm{Hu}$ activity, and excitation of $\mathrm{CH}$ cells leads to an excitation of Hu. This, in turn, increases the IPSP frequency in the opposite $\mathrm{CH}$ cell. Interestingly, although $\mathrm{CH}$ and HS cells have identical preferred directions for ipsilateral motion stimuli, the ipsilateral output connections of HS cells are different in some respect. In contrast to $\mathrm{CH}$ cells, HS cells do not influence the activity of the ipsilateral $\mathrm{H} 1$ or $\mathrm{H} 2$ cells. This agrees with the finding that $\mathrm{CH}$ cells are presumably GABAergic, whereas HS cells are not (Meyer et al., 1986; Strausfeld et al., 1995). On the other hand, HS cells have a stronger influence on the Hu cell than do the $\mathrm{CH}$ cells. This influence is excitatory and goes both ways; i.e., depolarization excites $\mathrm{Hu}$, and hyperpolarization inhibits $\mathrm{Hu}$.

\section{Going around one loop}

If $\mathrm{CH}$ and $\mathrm{HS}$ cells on different sides of the brain can influence one another via their action on the heterolateral elements, then this influence should actually come back into the lobula plate from which the activity started because the same circuit exists twice in a mirror-symmetrical manner. To test this idea of "going around one loop," we performed experiments involving dual intracellular recordings from two cells within the same lobula plate, injecting current into one of them and observing the effect of this manipulation in the other one. The experiment shown in Figure $6 a-d$ gives one example of a recording from a cell pair, a $\mathrm{dCH}$ cell and an HSE cell (anatomy shown in Fig. $6 a$ ). Both cells were located in the right brain hemisphere and responded to rotatory motion stimuli the same way; they were excited by clockwise motion and inhibited by motion in the opposite direction (Fig. 6b). Because the EPSPs occurred simultaneously in the two recorded cells, we conclude that both cells receive input from the identical contralateral $\mathrm{H} 1$ and $\mathrm{H} 2$ cells. The simultaneous intracellular recording also allowed for a quantitative evaluation of postsynaptic signals in both cells. Figure $6 c$ shows the result of the average membrane potential in the HSE cell triggered by the large EPSPs (H2 input) in the $\mathrm{dCH}$ cell. Clearly, as expected from the example trace in Figure $6 b$, both signals rise simultaneously, with the EPSPs in the HSE cell being somewhat faster than those in the $\mathrm{dCH}$ cell. When the IPSPs in the $\mathrm{dCH}$ cell were used to trigger the signal average in the HSE cell, no significant PSPs were obtained (Fig. $6 d$ ). In contrast to $\mathrm{CH}$ cells, thus, HS cells do not seem to receive inhibitory input from the $\mathrm{Hu}$ cell.

In such a way, we performed dual intracellular recordings from two LPTCs within the same lobula plate in a total of 10 different flies, injected current of either polarity into one of them, and evaluated the resulting change of EPSP frequency in the respective other neuron. The results are summarized in Figure 6, $e$ and $f$. Indeed, we found a strong effect of current injection on the EPSP frequency in the respective other neuron. Depolarization as well as hyperpolarization of either $\mathrm{CH}$ or HS cells led to a change in EPSP frequency that had the same sign as the current injected; if the cell became more excited, the number of EPSPs 

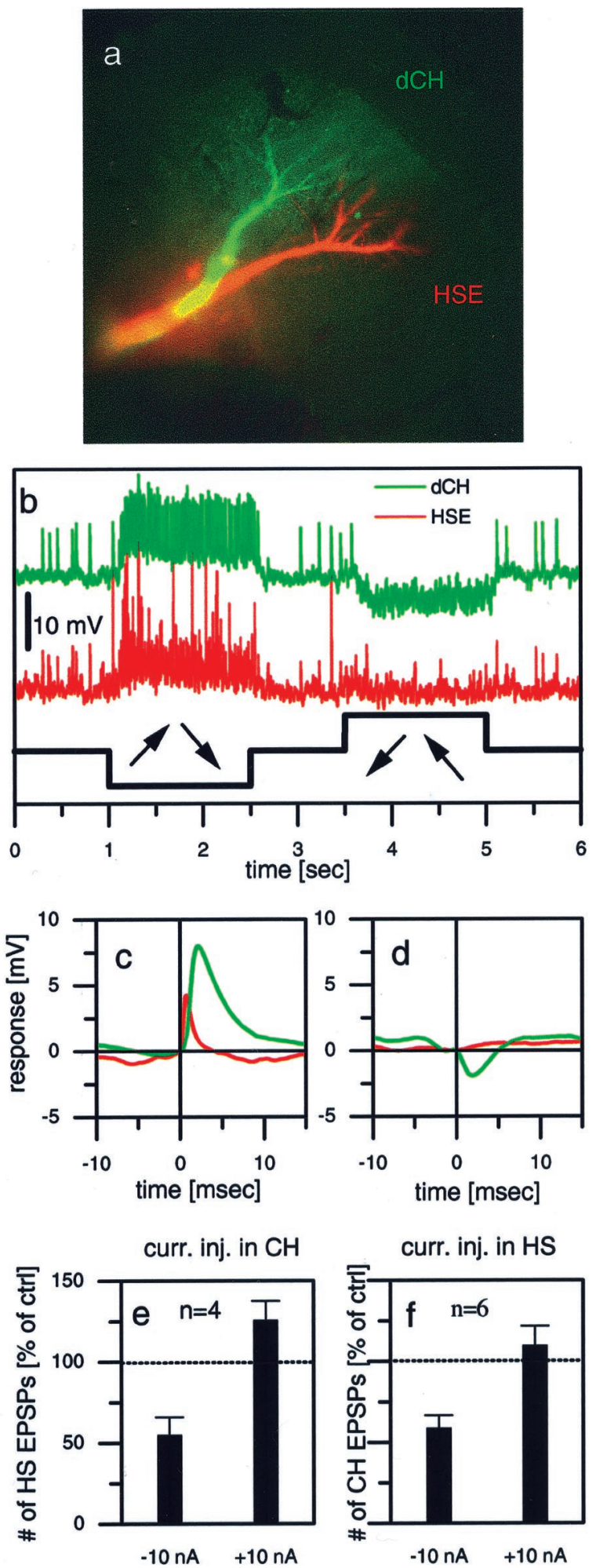

Figure 6. Dual intracellular recording of two LPTCs in the same brain hemisphere. $a-e$, Example responses from a dCH-HSE pair. $a$, Fluorescent micrograph of both cells, one filled with $\mathrm{Ca}$-green and the other with Alexa 568 (both from Molecular Probes). $b$, Visual responses of both cells to a rotatory motion stimuli in front of the fly. Because both cells have the same preferred direction, they jointly respond to motion in one direction with a depolarization and in the other direction with a hyperpolarization. $c$, Averaged HSE signals (red) triggered by large-amplitude EPSPs in the $\mathrm{dCH}$ cell ( green). $d$, Averaged HSE signals (red) triggered by IPSPs in the $\mathrm{dCH}$ cell (green). $e$, Average effect (mean $\pm \mathrm{SEM}$ ) of current injection into $\mathrm{CH}$ cells on the EPSP frequency observed in HS cells. Hyperpolar- slightly increased, and if the cell became more hyperpolarized, the number of EPSPs decreased. However, the effects were not of equal strength; hyperpolarizing the cell had a much more pronounced effect than had depolarizing the cell.

\section{DISCUSSION}

The circuit diagram (Fig. 1) summarizes our present knowledge about the connectivity of lobula plate neurons. While the heterolateral connections had been described previously (Hausen, 1977, 1981, 1984; Eckert and Dvorak, 1983; Haag, 1994; Haag et al., 1999; Horstmann et al., 2000), the experiments presented above add, as an important novel feature, ipsilateral connections to the circuit, leading to recurrent feedback loops in the system. Clearly, this kind of connectivity supports motion stimuli that lead to an asymmetric activity level in the lobula plates in both hemispheres such as rotatory motion.

In this context, an interesting question is whether we can assign a specific functional significance to the ipsilateral connections over the heterolateral ones. Would the neurons respond any differently without the ipsilateral connections, i.e., in a strict feedforward way without feedback? In the case of $\mathrm{CH}$ cells, the graded response component to binocular motion stimuli could be approximately explained as the sum of their responses to monocular stimuli (Egelhaaf et al., 1993). In this respect, thus, $\mathrm{CH}$ cells behave rather linear as, in a first approximation, would be expected from a feedforward circuitry without additional threshold nonlinearities. However, $\mathrm{H} 2$ neurons are different in this respect. As is illustrated in Figure 7, H2 responses to binocular stimuli are not a linear combination of their responses to monocular stimuli. Whereas the contralateral stimulus does not influence $\mathrm{H} 2$ activity at all when presented alone (Fig. 7, columns 1, 2), it does so strongly when given together with a monocular excitatory one (Fig. 7, columns 4, 5). Basically the same results were obtained when the contrast of the pattern was lowered from 87 to $20 \%$ (data not shown). This finding is hard to explain without the ipsilateral connectivity between LPTCs as shown in Figure 1. Besides its role in tuning the lobula plate neurons to rotatory motion stimuli, another possible role of the ipsilateral connections might be to enhance directional contrast within the visual field of one eye (Hausen, 1984), such as that occurring, e.g., during relative motion between objects and background or lateral expansions. Such a function would have been undetected by the flow fields used in the present study in which one eye was always stimulated homogeneously. Thus, to explore further the functional significance of the ipsilateral connections, more complex visual stimuli need to be applied in conjunction with single-cell ablation studies and quantitative modeling of the circuit. The latter two strategies are presently being pursued.

Another question pertains to the functional role of specific neurons in the lobula plate, like, e.g., the $\mathrm{H} 2$ cell. In addition to its function as a heterolateral element, the $\mathrm{H} 2$ cell could also

\section{$\leftarrow$}

ization of $\mathrm{CH}$ cells led to a decreased EPSP frequency in HS cells, whereas depolarization led to only a small increase in EPSP frequency. Data are from four experiments comprising the following cell pairs: $\mathrm{dCH}-\mathrm{HSN}(n=1)$, vCH-HSE $(n=1)$, and dCH-HSE $(n=2)$. $f$, Average effect (mean \pm SEM) of current injection into HS cells on the EPSP frequency observed in $\mathrm{CH}$ cells. Hyperpolarization of $\mathrm{HS}$ cells led to a decreased EPSP frequency in $\mathrm{CH}$ cells, whereas depolarization led to an EPSP frequency that was almost unchanged. Data are from six experiments comprising the following cell pairs: $\mathrm{dCH}-\mathrm{HSN}(n=2)$, vCH-HSN $(n=2)$, and dCH-HSE $(n=2)$. 

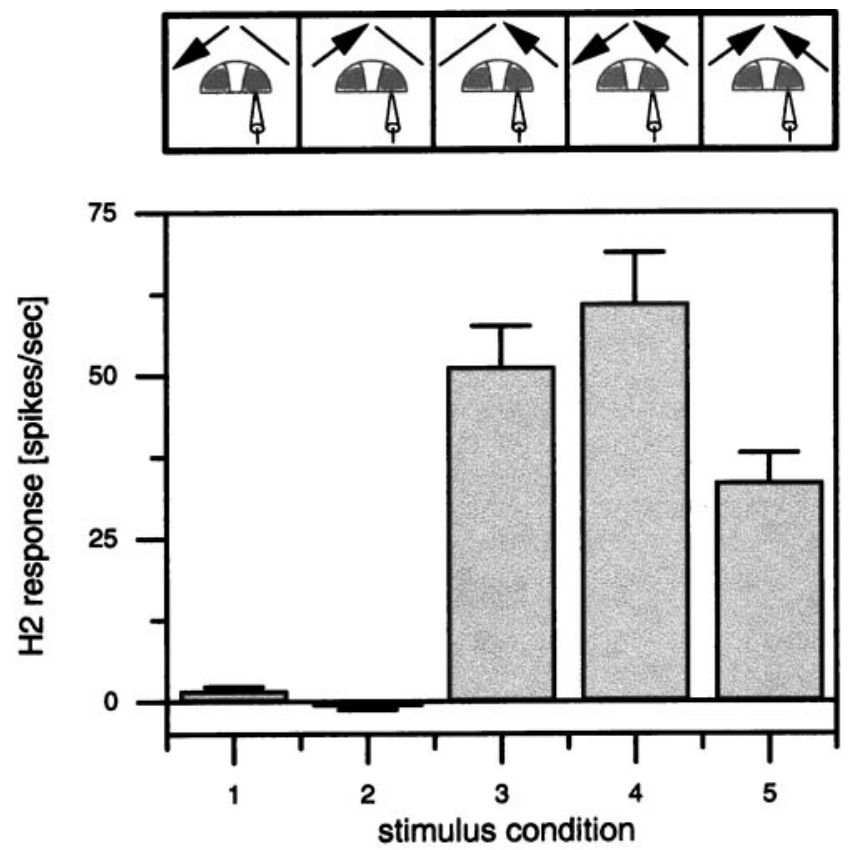

Figure 7. Average responses of five $\mathrm{H} 2$ cells \pm SEM during a $2 \mathrm{sec}$ presentation of the visual stimulus. Top, The stimulus conditions. Bottom, The responses. Note that although the cells do not respond to unilateral motion in front of the left eye in either direction (columns 1, 2), addition of this stimulus to a back-to-front stimulus in front of the right eye influences the response in a directionally selective way (compare columns 4, 5).

provide synaptic input directly onto descending neurons, thus being of more immediate behavioral relevance. Because the location where $\mathrm{H} 2$ has its axon terminals and contacts $\mathrm{CH}$ and $\mathrm{HS}$ cells is also the place where descending neurons have their dendritic ramifications (Gronenberg et al., 1995; Strausfeld et al., 1995), such a scenario seems completely feasible. Another more indirect role of $\mathrm{H} 2$ cell activity could be via its EPSPs, either in $\mathrm{CH}$ cells or in HS cells where the large EPSPs are known to often elicit action potentials (Haag et al., 1999). Such a possibility, however, is purely speculative because, at present, it is not known what aspects of the electrical signals in either the $\mathrm{CH}$ cells or HS cells are passed preferentially onto postsynaptic neurons.

Compared with the exclusive responsiveness of some descending neurons recorded, e.g., in the cervical connective (Borst, 1991), the selectivity described here for LPTCs is less pronounced. It seems that the flow-field specificity is being built up gradually in the fly visual system, from the neurons in the lobula plate, which display some nonlinear receptive field features such as expressed, e.g., in the strong preference in $\mathrm{H} 2$ cells for binocular rotatory motion stimuli, up to later processing stages. In any case, with its limited number of neurons and their accessibility for simultaneous electrical and/or optical recordings, the circuit of lobula plate neurons will provide a good model system in which the mechanisms underlying receptive field properties can be studied in great detail, leading to a precise understanding of how the response selectivity of visual interneurons for specific flow fields occurs.

\section{REFERENCES}

Bialek W, Rieke F, de Ruyter van Steveninck R, Warland D (1991) Reading a neural code. Science 252:1854-1857.

Borst A (1991). Fly visual interneurons responsive to image expansion. Zool Jb Physiol 95:305-313.
Borst A, Egelhaaf M (1989) Principles of visual motion detection. Trends Neurosci 12:297-306.

Borst A, Egelhaaf M (1990) Direction selectivity of fly motion-sensitive neurons is computed in a two-stage process. Proc Natl Acad Sci USA 87:9363-9367.

Borst A, Haag J (1996) The intrinsic electrophysiological characteristics of fly lobula plate tangential cells. I. Passive membrane properties. J Comput Neurosci 3:313-336.

de Ruyter van Steveninck R, Lewen GD, Strong SP, Koberle R, Bialek W (1997) Reproducibility and variability in neural spike trains. Science 275:1805-1808.

Duffy CJ, Wurtz RH (1991a) Sensitivity of MST neurons to optic flow stimuli. I. A continuum of response selectivity to large-field stimuli. J Neurophysiol 65:1329-1345.

Duffy CJ, Wurtz RH (1991b) Sensitivity of MST neurons to optic flow stimuli. II. Mechanisms of response selectivity revealed by small-field stimuli. J Neurophysiol 65:1346-1359.

Eckert H (1980) Functional properties of the H1-neurone in the third optic ganglion of the blowfly, Phaenicia. J Comp Physiol [A] 135:29-39.

Eckert H, Dvorak DR (1983) The centrifugal horizontal cells in the lobula plate of the blowfly Phaenicia sericata. J Insect Physiol 29:547-560.

Eckert H, Meller K (1981) Synaptic structures of identified, motionsensitive interneurones in the brain of the fly, Phaenicia. Verh Dtsch Zool Ges 1981:179.

Egelhaaf M, Borst A, Warzecha AK, Flecks S, Wildemann A (1993) Neural circuit tuning fly visual neurons to motion of small objects. II. Input organization of inhibitory circuit elements revealed by electrophysiological and optical recording techniques. J Neurophysiol 69:340-351.

Gauck V, Egelhaaf M, Borst A (1997) Synapse distribution on VCH, an inhibitory, motion-sensitive interneuron in the fly visual system. J Comp Neurol 381:489-499.

Gronenberg W, Milde JJ, Strausfeld NJ (1995) Oculomotor control in calliphorid flies: organization of descending neurons to neck motor neurons responding to visual stimuli. J Comp Neurol 361:267-284.

Haag J (1994) Aktive und passive Membraneigenschaften bewegungsempfindlicher Interneurone der Schmeissfliege Calliphora erythrocephala. PhD thesis, Tuebingen.

Haag J, Borst A (1996) Amplification of high-frequency synaptic inputs by active dendritic membrane processes. Nature 379:639-641.

Haag J, Borst A (1997) Encoding of visual motion information and reliability in spiking and graded potential neurons. J Neurosci 17:4809-4819.

Haag J, Borst A (1998) Active membrane properties and signal encoding in graded potential neurons. J Neurosci 18:7972-7986.

Haag J, Theunissen F, Borst A (1997) The intrinsic electrophysiological characteristics of fly lobula plate tangential cells. II. Active membrane properties. J Comput Neurosci 4:349-369.

Haag J, Vermeulen A, Borst A (1999) The intrinsic electrophysiological characteristics of fly lobula plate tangential cells. III. Visual response properties. J Comput Neurosci 7:213-234.

Hausen K (1977) Struktur, Funktion und Konnektivität bewegungsempfindlicher Interneurone im dritten optischen Neuropil der Schmeissfliege Calliphora erythrocephala. $\mathrm{PhD}$ thesis, Tuebingen.

Hausen K (1981) Monocular and binocular computation of motion in the lobula plate of the fly. Verh Dtsch Zool Ges 74:49-70.

Hausen K (1982a) Motion sensitive interneurons in the optomotor system of the fly. I. The horizontal cells: structure and signals. Biol Cybern 45:143-156.

Hausen K (1982b) Motion sensitive interneurons in the optomotor system of the fly. II. The horizontal cells: receptive field organization and response characteristics. Biol Cybern 46:67-79.

Hausen K (1984) The lobula-complex of the fly: structure, function and significance in visual behaviour. In: Photoreception and vision in invertebrates (Ali MA, ed), pp 523-559. New York: Plenum.

Hausen K, Wolburg-Buchholz K, Ribi WA (1980) The synaptic organization of visual interneurons in the lobula complex of flies. Cell Tissue Res 208:371-387.

Hengstenberg R (1977) Spike response of "non-spiking" visual interneurone. Nature 270:338-340.

Hengstenberg R (1982) Common visual response properties of giant vertical cells in the lobula plate of the blowfly Calliphora. J Comp Physiol [A] 149:179-193.

Hengstenberg R, Hausen K, Hengstenberg B (1982) The number and structure of giant vertical cells (VS) in the lobula plate of the blowfly Calliphora erytrocephala. J Comp Physiol [A] 149:163-177.

Horstmann W, Egelhaaf M, Warzecha AK (2000) Synaptic interactions increase optic flow specificity. Eur J Neurosci 12:2157-2165.

Krapp HG, Hengstenberg R (1996) Estimation of self-motion by optic flow processing in single visual interneurons. Nature 384:463-466. 
Krapp HG, Hengstenberg B, Hengstenberg R (1998) Dendritic structure and receptive-field organization of optic flow processing interneurons in the fly. J Neurophysiol 79:1902-1917.

McCann GD, Foster S (1971) Binocular interactions of motion detection fibres in the optic lobes of flies. Kybernetik 8:193-203.

Meyer E, Manute C, Streit P, Naessel D (1986) Insect optic lobe neurons identifiable with monoclonal antibodies to GABA. Histochemistry 84:207-216.

Rauschecker JP, von Grünau MW, Poulin C (1987) Centrifugal organization of direction preferences in the cat's lateral suprasylvian visual cortex and its relation to flow field processing. J Neurosci 7:943-958.

Single S, Borst A (1998) Dendritic integration and its role in computing image velocity. Science 281:1848-1850.

Single S, Haag J, Borst A (1997) Dendritic computation of direction selectivity and gain control in visual interneurons. J Neurosci 17:6023-6030.
Strausfeld NJ, Kong A, Milde JJ, Gilbert C, Ramaiah L (1995) Oculomotor control in calliphorid flies: GABAergic organization in heterolateral inhibitory pathways. J Comp Neurol 361:298-320.

Tanaka K, Saito H (1989) Analysis of motion of the visual field by direction, expansion/contraction, and rotation cells clustered in the dorsal part of the medial superior temporal area of the macaque monkey. J Neurophysiol 62:626-641.

Tanaka K, Fukada Y, Saito H (1989) Underlying mechanisms of the response specificity of expansion/contraction and rotation cells in the dorsal part of the medial superior temporal area of the macaque monkey. J Neurophysiol 62:642-656.

Wang Y, Frost BJ (1992) Time to collision is signalled by neurons in the nucleus rotundus of pigeons. Nature 356:236-238.

Wylie DRW, Frost BJ (1999) Responses of neurons in the nucleus of the basal optic root to translation and rotational flowfields. J Neurophysiol $81: 267-276$ 